Review Article

\title{
Remineralizing and anticariogenic benefits of puremilk - A review
}

\section{Ishani Vakil ${ }^{1}$, Vabitha Shetty ${ }^{2} \&$ Amitha M. Hegde ${ }^{3}$}

${ }^{1}$ Post graduate student, ${ }^{2}$ Professor and Post Graduate $\&{ }^{3}$ Senior Professor and H.O.D, Department of Pedodontics \& Preventive Dentistry, A. B. Shetty M emorial Institute of Dental Sciences, M angalore.

*Corresponding Author : IshaniVakil, Post graduate, Department of Pedodontics \& Preventive Dentistry, A. B. Shetty M emorial Institute of Dental Sciences, Mangalore. Mobile : +919742559863 E-mail : drishanivakil@gmail.com.

Received

: 17-07-2015

Review Completed : 25-01-2016

Accepted

:05-03-2016

Keywords : Milk, remineralization, anticariogenic, casein, CPP-ACP

Access this article online Quick Response Code

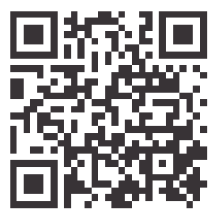

\section{Abstract :}

Caries initiation is associated with demineralization of the subsurface tooth enamel. At this early stage, the caries lesion is reversible via a remineralization process involving the diffusion of calcium and phosphate ions into the subsurface lesion to restore the lost tooth structure. However, children with high caries risk who have an increased and/or repeated episodes of demineralization require additional strategies to enhance remineralization. Today bioactive agents based on milk products have been developed in order to release elements that enhance remineralization of the enamel and dentine under cariogenic conditions. However, there is limited information on the remineralization potential of milk and milk products.

\section{Introduction}

From the very first day of life, breast milk forms the staple diet of children until the weaning period. Humans feed their infants with not only their own milk, but also animal milk and have also devised ways to cater to the needs of infants. ${ }^{1}$ Extensive research has reported diverse and compelling advantages for infants, mothers, families and society from breastfeeding. These advantages include health, nutritional, physical, immunological, developmental, psychological, social, economic and environmental benefits. ${ }^{2}$

Milk is an excellent protein food that provides essential amino acids and organic nitrogen for humans and animals of all ages ${ }^{3}$. Milk and milk products, such as cheese have been shown to exhibit anticariogenic properties in humans and animal models., ${ }^{4}$ Dairy products were recognized in the late 1950s as a food group that is effective in preventing dental caries. Epidemiological studies indicate children and adolescents with a low incidence of dental caries drank more milkthan thosewith a high caries incidence.

Milk has been defined as "a complex colloidal mixture of proteins, fat, lactose, minerals and many other constituents, some in suspension and some in solution. ${ }^{~}{ }^{7} \mathrm{It}$ is an emulsion of fat globules and a suspension of casein micelles (composed of casein, calcium, and phosphorous), all suspended in an aqueous phase that contains solubilized lactose, whey protein, some minerals and salts. ${ }^{8}$

M ilk contains $4-5 \%$ of the disaccharide lactose, which can be fermented by oral biofilm bacteria; however, unless the bacteria are adapted to lactose, fermentation is significantly less than from sucrose. ${ }^{9}{ }^{10}$ normally sucrose lowers the pH below 5.0 whereas lactose lowers it to around 6.0. With some individual variations, $\mathrm{pH}$ lower than 5.5 is hazardous to tooth enamel and lower than 6.2 to root tissues. Thus under normal conditions the carbohydrate content of milk confers a low cariogenic potential to milk and dairy products. Further, drinking milk or chewing on 
cheese counteracts the acidification induced by sucrose in the dental biofilm and diminishes period of acidification and demineralization, thus contributes to tooth preservation. $^{9}$

In the oral environment tooth structure undergoes continuous demineralization and remineralization. ${ }^{11,12}$ If this balance is disrupted, demineralization will progress, leading to a deterioration of the tooth structure. Caries initiation is associated with demineralization of the subsurface tooth enamel. Calcium and phosphate are lost from the subsurface enamel, resulting in subsurface lesion. At this early stage, the caries lesion is reversible via a remineralization process involving the diffusion of calcium and phosphate ions into the subsurface lesion to restore the lost tooth structure. Naturally there is a process of deand re mineralization occurring in the oral cavity. However, in children with high caries risk, the need for strategies to enhance remineralization is essential.

Calcium and phosphate ions and casein, in particular in casein phosphopeptide amorphous calcium phosphate complexes (CPP-ACP), are mostly responsible for the anticariogenicproperties of dairy products. ${ }^{13}$ The casein phosphopeptides stabilizes amorphous calcium phosphate as clusters of bioavailable ions that remineralize enamel subsurface lesions (i.e enamel caries).

Today bioactive agents based on milk products have been developed in order release elements that enhance remineralization of the enamel and dentine under cariogenic conditions. ${ }^{14}$ these agents in a paste form like tooth mousses have been formulated to promote remineralization of carious lesion by maintaining a supersaturated state of enamel mineral. These agents are based on CPP-ACP nanocomplexes derived from bovine milk-protein, casein, calcium and phosphate. A number of subsequent studies have demonstrated CPP-ACP to have anti-cariogenic activity in laboratory, animal and human in situ experiments. ${ }^{15}$ However, there is sparse and conflicting information about the anti-cariogenic and remineralization potential about milk and its products. Controversies about Cariogenic and Anti-Cariogenic Properties of M ilk

\section{Cariogenicity of Milk}

Extensive research has reported diverse and compelling advantages for infants, mothers, families, and society from breastfeeding. These advantages include health, nutritional, physical, immunological, developmental, psychological, social, economic, and environmental benefits. $^{2}$

To date, information about the cariogenicity or cariostatic properties of milk is surprisingly sparse. ${ }^{16} i t$ has been suggested that both bovine and human breast milk can cause dental caries in infants if consumed frequently and retained for long periods in mouth. ${ }^{17}$ Prolonged and excessive breastfeeding has also been suspected as a causative factor of early childhood caries. However, controversy exists regarding the cariogenicity of human breast milk. Human breast milk has higher carbohydrate content and lower calcium, phosphorous and protein levels than bovine milk, thus making it potentially more cariogenic. $^{18}$

It is a common household practice to add sugar to bovine milk to make it more palatable for infants. Recent studies indicate that milk containing sucrose is more cariogenic than milk alone $e^{16}$. As a fermentable carbohydrate, sugar acts a food for caries-producing microorganism, thus enhancing their growth and colonization on infants, newly erupted teeth, making them more susceptible to acid decay and caries inititation. . $^{190}$

\section{Anticariogenicity of Milk}

Bovine milk is generally regarded as being protective against caries, mainly due to high calcium and phosphorous, but also because of buffering capacity of the milk protein. Human milk differs significantly from bovine milk in several ways likely to increase the cariogenicity. Human milk has more lactose and less calcium, phosphorous and protein. ${ }^{21}$

It has also been suggested that milk fat could also prevent dental caries, either through a physical or a microbiological mechanism; former minimizes the adherence of the food to the tooth surface, while the latter involves the 
bacteriostatic properties of medium chain fatty acids. ${ }^{22}$

Complexes between casein phosphoproteins and amorphous calcium phosphate complexes have been shown to exert anticariogenic effects in laboratory, animal and human in situ caries models. This complex maintains the plaque fluid in a state of super saturation with respect to tooth enamel for both calcium and phosphate ions which suppresses demineralization and enhances remineralization. ${ }^{23}$

An in situ study investigated the capacity of CPP-ACP, when added to bovine milk to remineralize enamel subsurface lesion. They concluded that the addition of CPP-ACP to bovine milk significantly enhanced remineralization of enamel subsurface lesions in situ when subjects consumed $100 \mathrm{~mL}$ of milk daily for 30 sec for a 15 day period. ${ }^{24}$

Milk is one of the major diet for pre-school children, but its role in producing dental caries has been controversial. Jacobi (1862) stated that milk was cariogenic and responsible for massive destruction of the teeth in infants ${ }^{25}$. The same findings were observed by Vienna (1971) whereas Weiss(1966) has shown that milk protected enamel against demineralization and in a subsequent study identified the milk protein, casein as being responsible for acid production ${ }^{26,27}$. Tendon et al (1997) evaluated the cariogenic potential of different types of milk and milk formula in pre-school children. It was concluded from the study that bovine milk and human milk may be considered to be less cariogenic and more protective against dental caries, when compared to milk formula. ${ }^{28}$

Herod has drawn attention to the buffering action of dental plaque $\mathrm{pH}$ by saliva stimulated by chewing cheese, amino acids in casein and other milk proteins and the role of phosphoproteins, with the conclusion that continued research is needed on the chemical and physical characteristics of cheese ${ }^{29}$. This of course applies to other dairy products.

Hegde et al compared the caries protective potential of whole bovine milk and whole human milk. The results of the study suggested that the milk fractions namely casein, whey protein, lactose and milk fat were individually more caries protective in bovine milk when compared to the corresponding fractions in human milk. ${ }^{30}$

Epidemiological studies in recent years indicate children ${ }^{31}$ and adolescents ${ }^{32}$ with low incidence of dental caries drank more milk than those with high caries incidence. Elderly people who ate cheese several times per week had a lower incidence of root surface caries development. ${ }^{33}$ several reviews describe the role of milk and dairy products in dental caries prevention. ${ }^{34-36}$

Although in vitro studies have greatly improved our understanding of demineralization and remineralization process, it cannot simulate the complex nature of oral environment.

Tooth decay is a series of interactions that occur on a tooth surface, and remains a critical problem despite advances made in fluoridation of water and tooth pastes. Research data outlined in this review presents a strong case that dairy- derived bioactive peptides reduce dental caries in human enamel using in vitro methods.

\section{Human Milk}

The protein content of human milk decreases rapidly during the first month of lactationand declines much more slowly after that ${ }^{37}$. Most proteins are synthesized by the mammary gland, with a few possible exceptions, such as serum albumin (which appears from the maternal circulation). Milk proteins can be classified into 3 groups: mucins, caseins, and whey proteins. Mucins, also known as milk fat globule membrane proteins, surround the lipid globules in milk and contribute only a small percentage of the total protein content of human milk ${ }^{38}$. Because the fat content of human milk does not vary during the course of lactation, the milk mucin concentration is most likely constant, although little information is available concerning thistopic.

The contents of casein and whey proteins, however, change profoundly early in lactation; the concentration of whey proteins is very high, whereas casein is virtually 
undetectable during the first days of lactation. ${ }^{39,40}$ Subsequently, casein synthesis in the mammary gland and milk casein concentrations increases, whereas the concentration of total whey proteins decreases, partially because of an increased volume of milk being produced. As a consequence, there is no "fixed" ratio of whey to casein in human milk; it varies throughout lactation. The frequently cited ratio of 60:40 is an approximation of the ratio during the normal course of lactation, but it does vary from 80:20 in early lactation to 50:50 in late lactation. Because the amino acid compositions of caseins and whey proteins differ, the amino acid content of human milk also varies duringlactation.

Comparison between Human and Bovine Milk

\begin{tabular}{|l|c|c|}
\hline Casein & HUM AN M ILK & BOVINE M ILK \\
\hline Calcium & $\begin{array}{c}\text { Less than } \\
\text { bovine milk }\end{array}$ & $\begin{array}{c}\text { M ore than } \\
\text { human milk }\end{array}$ \\
\hline phosphate & Less & M ore \\
\hline Whey protein & Less & M ore \\
\hline Histidine & Less & M ore \\
\hline Organic acids & Less & M ore \\
\hline Enamel dissolution & More & less \\
\hline lactose & More & Less \\
\hline Bioactive peptides & More & Less \\
\hline
\end{tabular}

\section{Anticariogenic effect of Amorphous Calcium phosphate} stabilized by Casein Phosphopeptide ${ }^{41}$

Dental caries is initiated via the demineralizatiom of tooth hard tissue by organic acids from the fermentation of dietary sugar by dental plaque odontopathogenic bacteria. Even though, in most developing countries the prevalence of dental caries has decreased through the use of fluorides, the disease remains a major public health problem. Using laboratory, animal and human in situ caries models it has been shown that Casein Phosphopeptides Amorphous Calcium Phosphate Complex (CPP-ACP) exhibit anticariogenic activities. ${ }^{41}$

The CPP have a remarkable ability to stabilize calcium phosphate in solution and substantially increase the level of calcium in dental plaque. The proposed mechanism of anticariogenicity of CPP-ACP is that they localize ACP in dental plaque which buffers the free calcium and phosphate ion activities thereby helping to maintain a state of super saturation with respect to tooth enamel depressing demineralization and enhancing remineralization. ${ }^{41}$

Prolonged and exclusive breast-feeding has been associated with so many health benefits, along with reduced risks of gastrointestinal and respiratory infection, atopic eczema and other allergic diseases, and improved neurocognitive development. Evidence bearing on breastfeeding effects on dental caries, however, has been mixed and controversial. Several authorshave found human milk to be more cariogenic than cow milk, and it is clear from case reports and case series that breast-feeding, even exclusive breast-feeding, can cause caries in the maxillary incisors, similar to classic 'nursing bottle caries' in bottle fed infants. $^{9,} 42,43$ Some investigators have observed an increased risk and severity of caries associated with prolonged breast-feeding and night breast-feeding. ${ }^{44,45}$

\section{Conclusion}

Milk is an excellent protein food that provides essential amino acids and organic nitrogen for humans and animals of all ages. M ilk also contains factors that have protective properties such as calcium, phosphate, casein and lipids.

A considerable amount of research has been carried out on the dental properties of milk and milk products. Studies on the benefits of milk in caries control can be traced back more than 50 years. Research suggest that the benefits of milk and related products can be traced to several principal factors: remineralization of the tooth, prevention of bacterial attachment to the tooth and inhibition of bacterial biofilm formation ability. In addition to the most obvious beneficial factor, calcium, milk has also been shown to contain multiple proteins that serve a variety of functions important for health. ${ }^{46}$

Dairy products can be considered as physiological foods and precursors for several bioactive substances. However, further research is needed particularly in humans to fully substantiate the role of bioactive substances. Once the information regarding health benefits is accepted by the 
public, incorporation of whey protein and milk sugar in promotion of health benefits becomes a strong marketing tool.

Also there are other applications of remineralization potential of milk on various remineralizing agents containing CPP-ACP. The calcium phosphate based

\section{References}

1. Hurley WL. Human milk and lactation. [Online]. 2002[cited 2005 Sep 15]; Available from: URL:http:// www.classes.anci.uiuc.edu/ansc438

2. GartnerLM, Black LS, Eaton AP, Lawrence RA, Naylor AJ, Neifert EM, OHare D, Schanler RJ, Georgieff M, Piovanetti $Y$, Queenan J. Breastfeeding and the use of human milk. Pediatrics, 100(6):10359,1997

3. Lonnerdal B. Nutritional and physiological significance of human milk proteins.Am J clinNutr 2003; 77(suppl):1537S-43S.

4. Oshiro M, Yamaguchi K, Takamizaw T, Inage H, Watanabe T, Irokawa A, Ando S, M iyazaki M . Effect of CPP-ACP paste on tooth mineralization An FE-SEM study. Journal of Oral Sciences 2007; 49(2):115-120.

5. Harper DS, Osborn JC, Hefferren JJ, Clayton R. Cariostatic evaluation of cheeses with diverse physical and compositional characteristics. Caries Research 1986; 20:123-30.

6. Aimutis WR. Bioactive properties of milk proteins with particular focus on anticariogenesis. J Nutr 2004; 134:989S-995S.

7. Bowen WH, Pearson SK. Effect of milk on cariogenesis. Caries Res, 27:461-6, 1993.

8. Hurley WL. Milk Composition [Online].2002[cited 2005Sep15]; Availablefrom:URL:http:// www.classes.ansci.uiuc.edu/ansc438.

9. Rugg-Gunn AJ, Roberts GJ, and Wright WG: Effect of human milk on plaque $\mathrm{pH}$ in situ and enamel dissolution in vitro compared with bovine milk, lactose, and sucrose. Caries Res 1985;19:327-34

10. Birkhed D, Imfeld T, Edwardsson S: pH changes in human dental plaque from lactose and milk before and after adaptation. Caries Res 1993; 27:43-50.

11. Featherstone JD. The science and practice of caries prevention. Journal of American Dental Association 2000; 131:887-99.

12. Featherstone JD. The continuum of dental caries-evidence for dynamic disease process. Journal of Dental Research 2004; 83:C39C42. [Spec Iss C]

13. Reynolds EC. Anticariogenic complexes of amorphous calcium phosphate stabilized by casein phosphopeptides: a review. Spec Care Dentist 1998; 18:8-16.

14. Rahiotis C, Vougiouklakis G. Effect of a CPP-ACP agent on the demineralization and remineralization of dentine in vitro. Journal of Dentistry 2007; 35:695-698.

15. Reynolds EC. Casein phosphopeptide-amorphous calcium phospate and the remineralization of enamel. USDENTISTRY 2006:51-54

16. Bowen WH,Pearson SK. Effect of milk on cariogenesis. Caries Res, 27:461-6.1993

17. Birkhed D, Imfeld T, Edwardsson S. pH changes in human dental plaque from lactose and milk before and after adaptation. Caries Res, 27:4350, 1993.

18. Erickson PR, M azhari E. Investigation of the role of human breast milk in caries development. Pediatr Dent,21:86-90,1999

19. Ribeiro NM E, Ribeiro M AS. Breastfeeding and early childhood caries: a critical review. J pediatr (Rio J), 80(5 Suppl0): S199-210, 2004

20. Seow WK. Biological mechanisms of early childhood caries. Community Dent Oral Epidemiol, 26 Suppl 1:8-27, 1998.

21. Rugg-Gunn a J, Roberts G J, Wright W G. Effect of human milk on plaque in situ and enamel dissolution in vitro compared with bovine milk, lactose and sucrose. Caries Research 1985:19; 327-334.

22. Warner E A, Kanekanian A D, Andrews A T. Bioactivity of milk proteins: Anticariogenicity of whey proteins. International Journal of dairy remineralization technologies show promise as an adjunctive treatments to fluoride therapy in the noninvasive management of early carious lesions by CPP-ACP complex. Remineralizatiom of early carious lesion by CPPACP complex may continue to emerge in importance as fluoride did in the past for caries prevention and reduction.

technology 2001:54:4;151-153

23. Paula Moynihan. Food and factors that protect against dental caries.Nutrition Bulletin 2000:25(4):281-286

24. Goldman AS. The immune system of human milk: antimicrobial, antiinflammatory, and immunomodulating properties. Pediatr Infect Dis J $1993 ; 12: 664-72$

25. Jacobi. The dentition and its dearrangement course of lectures delivered in New York M edical College, 1862

26. Vienna. Cariogenic potential of milk. Thesis of Indiana School of Dentistry, 1971

27. Weiss ME, Bibby BG.: Effect of milk on enamel solubility. Arch Oral Biol 1966; 11: 49-57.

28. Tandon S, Shankar M, Gopinath VK, Moorthy K. Comparitive evaluation of cariogenic potential of different types of milk and milk formula in pre-school children. J Indian SocPedoPrev Dent 1997; 15 2:64-68.

29. Herod EL. The effect of cheese on dental caries: a review of the literature. Australian Dental Journal 1991; 36: 120-35

30. Hegde AM, Naik N. Comparison of salivary calcium, phosphate and alkaline phosphatase levels in children with early childhood caries after administration of milk, cheese and GC tooth mousse. An in vivo study. Journal of Clinical Pediatric Dentistry. 2014; 38(4).

31. Petti. S, Simonetti R, D'ArcaSimonetti A. The effect of milk and sucrose consumption in 6- to 11- year old Italian school children. Eur. J. Epidemiol 1997; 13: 659-664.

32. Petridou E, Athanassouli $t$, Panagopoulos $H$, Revinthi $K$. Sociodemographic and dietary factors in relation to dental health among Greek adolescents. Community Dent. Oral Epidemiol 1996; 24 307-311

33. Papas A, Joshi, Belangar A J, Kent R L, Palmer CA, Depaola P F. Dietary models of root caries. Am. J Clin. Nutr. 1995: 61: 417S-422S

34. M oynihan. Foods and factors that protect against dental caries. Nutr. Bull. 2000; 25: 281-286.

35. Kashket S, Depaola D P. Cheese consumption and the development and progression of dental caries. Nutr. Rev2002; 60: 97-103

36. Johansson I. M ilk and dairy products: possible effects on dental health ScanJ Nutr Rev. 2002; 46:119-122.

37. Lönnerdal B, Forsum E, Hambraeus L. A longitudinal study of the protein, nitrogen and lactose contents of human milk from Swedish well-nourished mothers. Am J ClinNutr 1976; 29:1127-33?

38. Patton S, Houston GE. A method for isolation of milk fat globules. Lipids 1986; 21:170-174.

39. Kunz C, Lönnerdal B. Human-milk proteins: analysis of casein and casein subunits by anion-exchange chromatography, gel electrophoresis, and specific staining methods. Am J ClinNutr 1990; 51:37-46?

40. Kunz C, Lönnerdal B. Re-evaluation of the whey protein/casein ratio of human milk. ActaPaediatr 1992; 81:107-12.

41. Reynolds EC,Cai F, Shen P, Walker GD. Retention in plaque and remineralization of enamel lesions by various forms of calcium in mouthrinse or sugar-free chewing gum.J Dent Res2003;82:206-11.

42. Bowen WH, Lawrence RA: Comparison of the cariogenicity of cola, honey, cow milk, human milk, and sucrose. Pediatrics 2005; 116: 921-926.

43. Gardener DE, Norwood JR, Eisenson JE: At-will breast feeding and 
dental caries: four case reports. J Dent Res 1977; 44:186-191.

44. Weerheijm KL, Uyttendaele-Speybrouck BFM, Euwe HC, Groen HJ: Prolonged demand breast-feeding and nursing caries. Caries Res 1998; 32:46-50.

45. Matee MIN, van't Hof MA, Maselle SY, Mikx FHM, van PalensteinHelderman WH: Nursing caries, linear hypoplasia and weaning habits in Tanzanian infants. Community Dent Oral Epidemiol 1994; 22:289-291.

46. Reynolds EC, Cai F, Shen P, Walker GD. Retention in plaque and remineralization of enamel lesions by various forms of calcium in a mouthrinse or sugar-free chewing gum. J Dent Res. 2003; 82(3):20611. 